\title{
Utilidad de la medicina nuclear en el diagnóstico del divertículo de Meckel
}

\section{Usefulness of nuclear medicine in the diagnosis of Meckel's diverticulum}

\author{
Eiber Alexis Briones-Velázquez, ${ }^{*,+}$ Sarai Páez-Moreno ${ }^{\ddagger}$ \\ * Residente de Medicina Nuclear e Imageneología Molecular. Hospital de Especialidades \\ “Dr. Antonio Fraga Mouret” del Centro Médico Nacional La Raza; ${ }^{\ddagger}$ Anatomía Patológica. Hospital \\ General de Zona No. 5, Instituto Mexicano del Seguro Social, Ciudad de México.
}

\section{RESUMEN}

Se presentan las imágenes de un divertículo de Meckel por gammagrafía convencional y por tomografía por emisión de fotón único (SPECT), empleando el radioisótopo tecnecio-99 metaestable $\left({ }^{99 \mathrm{~m}} \mathrm{Tc}\right)$, en un paciente escolar en quien se confirmó por cirugía e histopatología.

Palabras clave: Divertículo de Meckel, gammagrafía, tomografía por emisión de fotón único, tecnecio-99.

\begin{abstract}
We present the images of a Meckel's diverticulum by conventional scintigraphy and by single photon emission tomography (SPECT), using the metastable technetium-99 radioisotope (99mTc), in an 8-year-old patient, in whom the diagnosis was confirmed by surgery and histopathology
\end{abstract}

Keywords: Meckel diverticulum, scintigraphy, single photon emission tomography, technetium-99.

- Su edad de presentación se observa comúnmente antes de los dos años.

- Suele localizarse a dos pies (60 centímetros) de la válvula ileocecal en el borde anti-mesentérico.

- Macroscópicamente suele medir $2 \mathrm{~cm}$ de diámetro y 2 pulgadas $(5 \mathrm{~cm})$ de longitud.

- Histológicamente suele contener dos tipos de tejido heterotrópico: gástrico y pancreático.

La mayoría de los portadores de un divertículo de Meckel son asintomáticos, en caso de presentar alguna manifestación clínica, la más observada es la hemorragia digestiva baja indolora, que es secundaria a la ulceración de la mucosa intestinal causada por la secreción del tejido heterotrópico. Otras formas de presentación clínica menos frecuentes son la invaginación intestinal, obstrucción intestinal, diverticulitis y perforación intestinal. ${ }^{3,4}$

Diferentes estudios de imagen se utilizan para orientar la sospecha clínica, como el ultrasonido, tomografía computarizada, resonancia magnética 
nuclear, gammagrafía convencional (GC) y tomografía por emisión de fotón único (SPECT). De estas dos últimas, la GC permite obtener imágenes dinámicas y estáticas de la región abdominopélvica, por su parte la SPECT permite obtener imágenes tomográficas de esta misma región, lo anterior empleando el radioisótopo tecnecio-99 metaestable $\left({ }^{99 \mathrm{~m}} \mathrm{Tc}\right)$. Este radioisótopo es captado y secretado por las células mucinosas del tejido gástrico heterotrópico, por lo que puede ser identificado por gammagrafía, siendo la sensibilidad del $80-85 \%$ y la especificidad del 85-95\%. 5,6

En este trabajo presentamos las imágenes de GC y la SPECT utilizando el radioisótopo ${ }^{99 \mathrm{~m} T c}$ para el diagnóstico en un paciente con divertículo de Meckel.

\section{PRESENTACIÓN DEL CASO}

Masculino de ocho años de edad sin antecedentes de importancia, inició su padecimiento dos semanas previas con evacuaciones hematoquécicas durante dos días, ocasionando disminución de hemoglobina hasta $5 \mathrm{mg} / \mathrm{dL}$, por lo que fue necesaria una transfusión de paquete globular en tres ocasiones.

Es referido al servicio de Medicina Nuclear, como parte del protocolo de estudio de sangrado digestivo, sospechando DM. En el momento de la realización de estos estudios, se encontraba estable sin cuadros de hematoquecia.

Para la preparación del paciente, se indicó un ayuno de cuatro horas, además de la administración de omeprazol. Para realizar la gammagrafía planar ini-
Figura 1:

Imágenes secuenciales de la región abdominopélvica. En las flechas se aprecia zona de captación anormal del radiofármaco, la cual es evidente a partir del minuto 5-6.

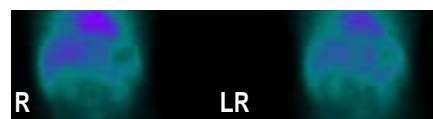

$1-2$

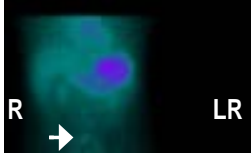

$11-12$

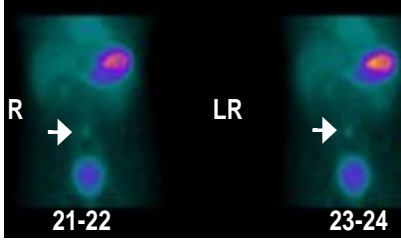

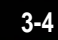

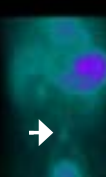

$13-14$
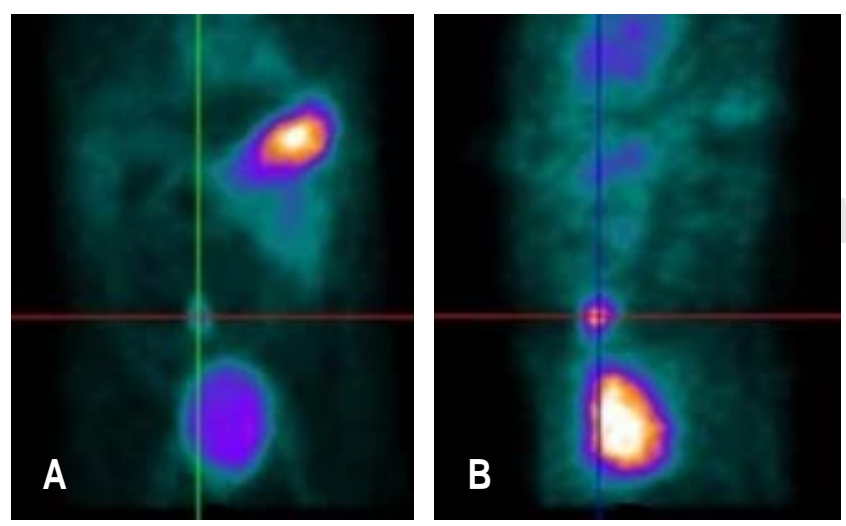

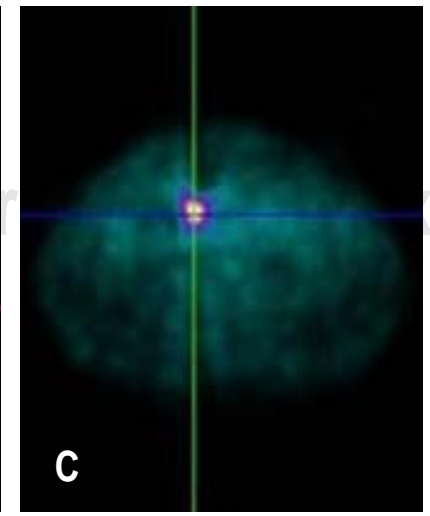

LR

LR

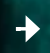

5-6

LR

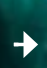

LR

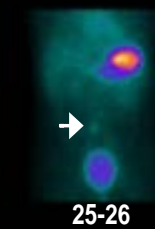

LR

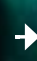

L

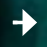

$7-8$

$9-10$

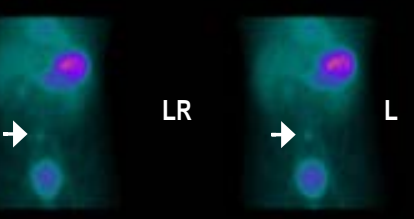

$17-18 \quad 19-20$
Figura 2:

Imágenes obtenidas por fusión y reconstrucción SPECT:

A) Corte coronal, B) corte sagital, C) corte axial. 
cialmente se administró vía intravenosa 66.6 megabequereles de ${ }^{99 \mathrm{~m}} \mathrm{Tc}$, y enseguida se adquirieron imágenes en proyección anterior de la región abdominopélvica en un equipo MEDISO doble cabezal, bajo las siguientes condiciones: imágenes dinámicas 1 imagen/segundo durante 1 minuto, imágenes estáticas 1 imagen/minuto durante 30 minutos, matriz $128 \times 128$ píxeles, zoom 1, colimador de baja energía y alta resolución (LEHR), fotópico centrado a 140 kiloelectronvoltios $(\mathrm{keV})$ con un ancho de ventana del $20 \%$.

Después se procedió a realizar un SPECT bajo las siguientes condiciones: $3^{\circ}$ por imagen durante 30 segundos hasta completar una rotación de $360^{\circ}$ con órbita circular, en una matriz de $128 \times 128$ píxeles, filtro de procesamiento Butterworth, zoom 1, LEHR, fotópico centrado a $140 \mathrm{keV}$ con un ancho de ventana del $20 \%{ }^{7}$

En las imágenes secuenciales de la región abdominopélvica se observa la biodistribución (corazón, trayectos vasculares de la aorta abdominal e iliofemoral, hígado y estómago) y la eliminación (renal y vías urinarias) habituales del radiofármaco. En las áreas señaladas con flechas, se aprecia una zona de captación anormal del radiofármaco, la cual es evidente a partir del minuto 5-6 y que se concentra de forma progresiva a lo largo del estudio, cuya intensidad es menor a la del estómago, el cual se utiliza como órgano de referencia (Figura 1).

Por SPECT, en las áreas señaladas con el cursor, se aprecia con mayor detalle la zona de captación anormal del radiofármaco inicialmente evidenciada en las

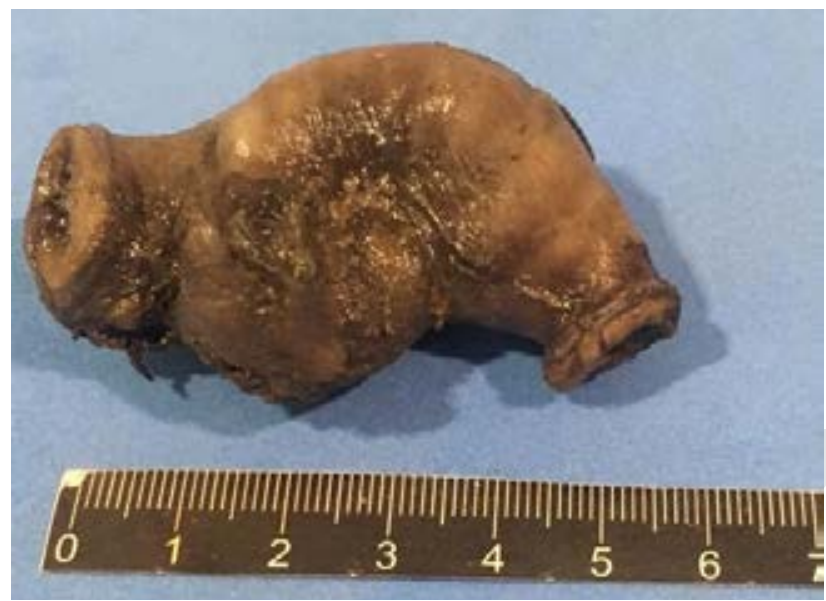

Figura 3: Imagen macroscópica del segmento de íleon resecado en la cual se evidencia el divertículo de Meckel (asterisco) $(2.0 \times 2.5 \mathrm{~cm})$.

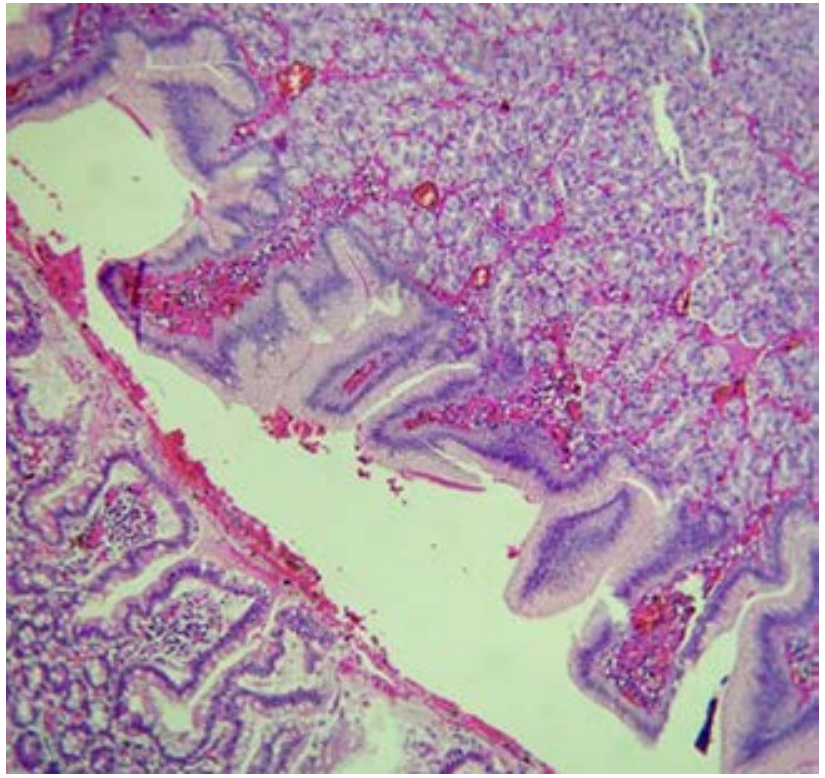

Figura 4: Corte histológico teñido con hematoxilina y eosina (200x): se observa continuación de mucosa de intestino delgado identificada por epitelio cilíndrico simple que alterna con células caliciformes. En zona diverticular se observa mucosa gástrica identificada por criptas con epitelio mucoproductor, con glándulas subyacentes de células oxínticas de citoplasma eosinófilo y capilares dilatados congestivos en estroma asterisco.

imágenes secuenciales, la cual se encuentra a nivel del cuadrante inferior derecho (CIF) (Figura 2).

La valoración de todas las imágenes indica claramente el aumento de la captación en el CIF, lo que sugiere la presencia de un DM, dichos hallazgos se corroboraron después de la intervención quirúrgica mediante el estudio histopatológico, el cual confirmó el diagnóstico de un $\mathrm{DM}$ con presencia de tejido gástrico (Figuras 3 y 4).

\section{REFERENCIAS}

1. Langman J, Sadler T. Digestive system. In: Langman J, Sadler T. Langman's medical embryology. 14th ed. Philadelphia, USA: Williams \& Wilkins; 2018. pp. 230-255.

2. Ruíz-Celorio M, Higuera-de-la-Tijera F, Pérez-Torres E. El divertículo de Meckel. Rev Med Hosp Gen Méx. 2014; 77(2): 88-92.

3. Kuru S, Kismet K. Meckel's diverticulum: clinical features, diagnosis and management. Rev Esp Enferm Dig. 2018; 110(10): 726-732.

4. Tarigo-Casella N, Vallverdú-Scorza M, Lyford-Pike P, Neirotti Rivero R. Diverticulitis de Meckel: a propósito de un caso clínico. Rev Méd Urug. 2017; 33(2): 149-151. 
5. O’Malley J, Ziessman H. Gastrointestinal system. In: O’Malley J, Ziessman H. Nuclear medicine: the requisites. 5 th ed. Philadelphia, USA: Elsevier; 2020. pp. 220-255.

6. Mettler F, Guiberteau M. Gastrointestinal tract. In: Mettler F, Guiberteau M. Essentials of nuclear medicine and molecular imaging. 7th ed. Philadelphia, USA: Elsevier; 2019. pp. 213242.

7. Spottswood S, Pfluger T, Bartold S, Brandon D, Burchell N, Delbeke $\mathrm{D}$ et al. SNMMI and EANM practice guideline for Meckel diverticulum scintigraphy 2.0. J Nucl Med Technol. 2014; 42: 163-169. 